\title{
O processo estrutural como forma de proteção aos direitos fundamentais ao meio
}

\section{ambiente}

The structural litigation as a form of protecting fundamental rights to the environment

El litigio estructural como forma de protección de los derechos fundamentales al medio ambiente

Recebido: 30/12/2020 | Revisado: 31/12/2020 | Aceito: 29/01/2021 | Publicado: 07/02/2021

Luana Pedrosa de Figueiredo Cruz

ORCID: https://orcid.org/0000-0001-6966-5260

Universidade de Itaúna, Brasil

E-mail: luanapedrosa@uol.com.br

Lincoln Machado Alves de Vasconcelos

ORCID: https://orcid.org/0000-0001-7168-8269

Universidade de Itaúna, Brasil

E-mail: lincolnmachadoadv@gmail.com

\begin{abstract}
Resumo
O presente artigo tem por objetivo analisar o processo de caráter estrutural como forma de proteção aos direitos fundamentais, em especial, o direito ambiental. Primeiramente, apresenta-se uma identificação do surgimento dessa categoria de litígios para identificar a sua relevância. Nesse contexto, apresenta-se a definição de litígio estrutural, com a possibilidade de decisões estruturantes emanadas do Poder Judiciário, diferenciando dos litígios de interesse público e das ações coletivas, para demonstrar que se trata de uma demanda mais complexa, que visa a correção ou prevenção do problema de forma sistêmica. A pesquisa é de natureza teórico-bibliográfica e documental, seguindo o método descritivo-analítico que instruiu a análise da legislação constitucional, infraconstitucional e jurisprudencial, bem como uso da doutrina. Conclui-se pela necessidade de utilização de processos estruturais para a concretização de direitos fundamentais, seja na forma preventiva ou reparatória, por trazer uma solução que vai muito além do problema que, inicialmente, provocou a necessidade de se recorrer ao judiciário.
\end{abstract}

Palavras-chave: Medidas estruturais; Direitos fundamentais; Meio ambiente; Ações coletivas.

\begin{abstract}
This article aims to analyze the structural process as a way of protecting fundamental rights, in particular, environmental law. First, an identification of the appearance of this category of litigation is presented to identify its relevance. In this context, the definition of structural litigation is presented, with the possibility of structural decisions emanating from the Judiciary, differentiating from public interest litigation and collective actions, to demonstrate that it is a more complex demand, aimed at correcting or prevention of the problem in a systemic way. The research is of theoretical-bibliographic and documentary nature, following the descriptive-analytical method that instructed the analysis of constitutional, infraconstitutional and jurisprudential legislation, as well as the use of doctrine. It concludes by the need to use structural processes for the realization of fundamental rights, either in preventive or reparative form, as it brings a solution that goes far beyond the problem that initially caused the need to resort to the Judiciary.

Keywords: Structural injunctions; Fundamental rights; Environment; Class actions.
\end{abstract}

\section{Resumen}

Este artículo tiene como objetivo analizar el litigio estructural como una forma de proteger los derechos fundamentales, en particular, el derecho ambiental. Primero, se presenta una identificación del surgimiento de esta categoría de litigio para identificar su relevancia. En este contexto, se presenta la definición de litigio estructural, con la posibilidad de estructurar decisiones emanadas del Poder Judicial, diferenciando el litigio de interés público y las acciones colectivas, para demostrar que se trata de una demanda más compleja, orientada a subsanar el problema de forma sistémica. La investigación es de carácter teórico-bibliográfico y documental, siguiendo el método descriptivoanalítico que instruyó el análisis de la legislación constitucional, infraconstitucional y jurisprudencial, así como el uso de la doctrina. Concluye por la necesidad de utilizar procesos estructurales para la realización de los derechos fundamentales, ya sea en forma preventiva o reparadora, ya que aporta una solución que va mucho más allá del problema que inicialmente motivó la necesidad de acudir al Poder Judicial.

Palabras clave: Medidas estructurales; Derechos fundamentales; Medio ambiente; Acciones colectivas. 


\section{Introdução}

$\mathrm{O}$ artigo tem por objeto o estudo do processo estrutural, notadamente no contexto da atual política governamental, que reduza capacidade de atuação das instituições voltadas para a manutenção de um meio ambiente ecologicamente equilibrado.

No primeiro tópico busca-se uma compreensão acerca do processo judicial de caráter estrutural. Nessa esteira, cumpre diferenciar o aludido processo estrutural - structural litigation - do processo de interesse público - public law litigation. Da mesma forma, distingue-se a ação coletiva 'regular' do processo estrutural, como etapa necessária à compreensão do recorte teórico proposto.

Em conclusão avalia-se a possibilidade da utilização do processo estrutural como meio para compelir o Estado a adotar, de forma perene, políticas públicas eficazes, livres de interferências políticas, para a defesa da biodiversidade brasileira.

\section{Metodologia}

Tendo em vista a necessidade de se perquirir perspectiva teórica pela qual os direitos fundamentais sejam concretizados mediante tutela adequada, analisa-se a utilização do processo estrutural como mecanismo para a promoção do direito ao meio ambiente ecologicamente equilibrado.

Nessa esteira é a lição de Ada Pellegrini Grinover (2016, p.34), ao discorrer sobre a tipologia dos conflitos:

Não é possível, evidentemente, identificar e classificar todos os conflitos, individuais e coletivos existentes na multiforme sociedade de hoje. Eles vão surgindo e ao processo cabe solucioná-los, haja ou não haja um instrumento específico para tanto.

Logo, reconhecida a necessidade de um mecanismo de tutela permeável às especificidades do caso concreto, incrementa-se a probabilidade da obtenção de provimento jurisdicional apto à proteção adequada dos direitos fundamentais. A partir da constatação acima, delimita-se o tema, mediante a proposta de se investigar um mecanismo mais eficiente de tutela jurisdicional dos direitos relativos ao meio ambiente ecologicamente equilibrado. Nesse giro, segundo Köche J.C. (2011, p. 129) a delimitação do problema esclarece os limites precisos da dúvida que tem o investigador dentro do tema escolhido.

Ademais, por essa perspectiva é que se robusteceria a busca pela concretização dos direitos fundamentais, como pontuado por Janaína Reckziegel (2013, p. 31):

Se o Estado brasileiro e mais especificamente o seu Poder Judiciário pretendem fazer garantir os direitos fundamentais [...] distensionando a assimetria de poder existente na sociedade civil, primeiro precisarão adaptar o seu aparelho a respeitar os direitos fundamentais que vêm historicamente violando e, em segundo, construindo um processo judicial que supere as práticas tradicionais acima apontadas, tendendo a se tornar um instrumento de concretização dos direitos fundamentais em todas as esferas do próprio Estado e da sociedade civil.

Para tanto, empreende-se pesquisa de natureza teórico-bibliográfica, mediante a análise de artigos científicos e doutrina. Além disso, imprescindível a pesquisa documental, notadamente no que se refere ao exame do julgamento da ação civil pública doravante minudenciada.

Tanto as proposições teóricas, quanto a análise da legislação constitucional, infraconstitucional e jurisprudencial, serão examinadas pelo método descritivo-analítico. Além disso, é realizada uma abordagem, em linhas gerais, sobre a origem do processo judicial de caráter estrutural, argumentando-se sobre sua aptidão para a tutela adequada e efetiva dos direitos fundamentais.

Posteriormente, sob a análise do direito ao meio ambiente ecologicamente equilibrado, seguida por estudo de caso e de doutrina revisada, pretende-se questionar sobre a reestruturação de políticas públicas mediante medidas estruturantes. 


\section{Resultados e Discussão}

\subsection{O processo judicial de caráter estrutural: origem do instituto}

Em um cenário no qual o país é assolado por sucessivos desastres ambientais, parece revigorado o debate em torno do processo de caráter estrutural, uma vez que tal fenômeno germinou justamente em um estado de inquietação.

Segundo Fredie Didier (2020, p. 104), o 'structural litigation' teria sua origem "em um estado de desconformidade". Além disso, o que se observa é que o comando constitucional tem sido constantemente violado ${ }^{1}$. Referido dispositivo estampa a vontade do constituinte e do povo, de que seja efetivado o direito ao meio ambiente ecologicamente equilibrado.

Há de se observar que, em larga escala, tem sido noticiada a inquietação e insatisfaçãó ${ }^{2}$ subjacentes ao nascedouro do processo estrutural. A preocupação não é local e, além de tudo, é sistêmica. E a necessidade de se implementarem políticas públicas estruturais é algo que não pode mais esperar. Nessa esteira, torna-se evidente a relevância dos denominados processos estruturais, que vão muito além de uma ação pontual para correção de um dano já ocorrido. Do contrário, referidas ações trazem propostas que vão muito além, conforme se observará a seguir.

A origem dos mencionados litígios estruturais remonta, segundo Marco Félix Jobim (2013, p. 30), aos anos de 1950 e 1960, notadamente em virtude do processamento do caso Brown v. Board of Education, nome dado a cinco casos separados que foram julgados pela Suprema Corte dos Estados Unidos.

Versava a lide sobre a problemática da segregação racial em escolas públicas. Os casos foram Brown v. Conselho de Educação de Topeka, Briggs v. Elliot, Davis v. Conselho de Educação de Prince Edward County, Bolling v. Sharpe e Gebhart v. Ethel $^{3}$. Não obstante os fatos de cada caso fossem distintos, a questão central em cada um era a constitucionalidade da segregação patrocinada pelo Estado nas escolas públicas.

Por mais que haja também a discussão de que o caso anteriormente citado não seja, genuinamente, um litígio estrutural, há de se concordar que é, provavelmente, na pior das hipóteses, um embrião muito próximo da realidade que hoje se conhece, e cuja premissa se pode extrair de forma indiscutível: a partir de uma provocação de um ou mais casos concretos, percebe-se que há necessidade de implementação de uma política pública mais ampla do que o problema que se pretende resolver, de início. Trata-se de casos que não surgiram necessariamente com a intenção de provocarem uma decisão estrutural, mas que acabaram nisso resultando por sua natureza.

Justamente pela 'policentria' do case acima, pela magnitude dos direitos e interesses aglutinados, verificável também em casos nos quais são reportadas violações estruturais de direitos, corolário de um apanhado de práticas institucionalizadas, é que se denomina tal processo de 'estrutural'.

A propósito, pertinente transcrever a lição de Owen Fiss (2017, p.120), para quem:

O processo judicial de caráter estrutural é aquele no qual um juiz, enfrentando uma burocracia estatal no que tange aos valores de âmbito constitucional, incumbe-se de reestruturar organização para eliminar a ameaça imposta a tais valores pelos arranjos institucionais existentes. Essa 'injunction' é o meio pelo qual essas diretivas de reconstrução são transmitidas.

\footnotetext{
${ }^{1}$ Constituição Federal, art. 225: Todos têm direito ao meio ambiente ecologicamente equilibrado, bem de uso comum do povo e essencial à sadia qualidade de vida, impondo-se ao Poder Público e à coletividade o dever de defendê-lo e preservá- lo para as presentes e futuras gerações. (BRASIL, 2019)

2 Consoante se depreende das reportagens estampadas nos principais periódicos do mundo, por todos: Amazon fires: Are they worse this year than before? Disponível em: https://www.bbc.com/news/world-latin-america-53893161.(Amazon, 2014)

${ }^{3}$ Para mais uma pesquisa aprofundada, redireciona-se o leitor ao sítio eletrônico da Suprema Corte Dos Estados Unidos da América, acessível pelo seguinte endereço eletrônico: https://www.uscourts.gov/educational-resources/educational-activities/history-brown-v-boardeducation-re-enactment
} 
A expressão 'policentria', com efeito, remeteria à imbricação de interesses, em panorama no qual o Judiciário é instado a implementar medidas estruturais, justamente em razão da peculiaridade das pretensões deduzidas em juízo.

\subsection{Processo coletivo $\mathrm{x}$ processo estrutural - uma diferenciação necessária}

Para tratar da diferença entre Processo Coletivo e Processo Estrutural, é necessário deixar claro que tampouco se confundem com o processo de interesse público, por mais que haja pontos de intersecção. O processo de interesse público - ou public law litigation (Chayes, 1976, p.35), não implicaria, necessariamente, a reorganização de uma estrutura burocrática. Ademais, compreenderia uma demanda que poderia ser individual ou coletiva e, por fim, volta-se essencialmente contra o Estado.

Já o processo de natureza estrutural, a seu turno, implicaria a reestruturação do modo de funcionamento institucional. Com efeito, teria a potencialidade de remodelar substancialmente determinadas práticas institucionais. Nesse caso, as demandas seriam coletivas ${ }^{4}$, podendo o Estado figurar ou não no polo passivo.

Edilson Vitorelli traz uma explicação muito precisa, demonstrando, inclusive, que há uma certa confusão mas que processo de interesse público e processo estrutural possuem origens acadêmicas distintas 5 .

Assevere-se que tampouco se pode confundir o conceito de demanda coletiva com a ideia de processo estrutural. Conforme a definição proposta por Luiz Manoel Gomes Júnior (2008, p.14), o conceito de ação coletiva compreenderia três aspectos fundamentais, quais sejam: um sistema de legitimidade diferenciada; um regime especial relativo à coisa julgada e, por fim, a dedução em juízo de pretensão relativa a um ou mais direitos coletivos.

Existiria pois, na sistemática processual coletiva, uma legitimação diferenciada, outorgada por lei àqueles que deduzem em juízo pretensões relativas a direitos coletivos em sentido amplo.

Em síntese, a atuação em juízo para a defesa de direitos coletivos não é representada por uma confluência entre a titularidade do direito material e a do direito processual. Dito de outro modo, conforme lição de Gomes e Cruz (2019, p.296):

O que vigora, no sistema coletivo, é a possibilidade de atuar em Juízo, para a defesa de uma categoria de direitos materiais que difere da individual, uma legitimidade deferida por expressa previsão legal, para a defesa dos direitos coletivos.

Conquanto os litígios de caráter estrutural compreendam, repise-se, uma demanda coletiva, com esta não se confundem. Aliás, as ações coletivas tal como sistematizadas no ordenamento jurídico vigente, sequer revelam-se propensas a proporcionar uma ingerência/fiscalidade democrática na construção do provimento jurisdicional ${ }^{6}$ - muito menos se prestariam a remodelar práticas institucionais, tal como se sucede, invariavelmente, no âmbito do processo estrutural.

\footnotetext{
${ }^{4}$ Segundo doutrina de Jordão Violin (2013), sufragando o argumento desenvolvido por Stephen Yeazell (1980).

${ }^{5}$ A ideia de structural litigation deriva do pensamento de Owen Fiss, a partir de 1979, enquanto Public Law Litigation é uma expressão cunhada por Abram Chayes, em 1976, para descrever um fenômeno que, na sua visão, não vem desde Brown, mas do século XIX: o aumento do número de leis destinadas não a resolver um conflito pretérito, bilateral, existente entre particulares, mas a regular e modificar arranjos sociais e econômicos, para o futuro. Em outras palavras, a decisão judicial deixa de pretender remediar o ilícito pretérito, como tradicionalmente ocorre, para buscar ajustar o comportamento futuro do réu. Isso gera a necessidade de um regime de execução prolongado, em vez de uma transferência instantânea de patrimônio. O processo se afasta, com isso, de seu perfil clássico. Além disso, litígios de interesse público, na visão de Chayes, incidem sobre "uma lesão relativa à operação de uma política pública". Levando os conceitos a sério: o processo estrutural, processo coletivo, processo estratégico e suas diferenças. Revista de Processo | vol. 284/2018 | p. 333 - 369 | Out / 2018.DTR\2018\19904

${ }^{6}$ Como defendido por Sérgio da Cruz Arenhart: "Isso porque, substancialmente, a tutela coletiva brasileira, grosso modo, pode ser resumida em um processo 'individual', no qual o autor da demanda se legitima à proteção de interesses de terceiros ou de toda coletividade. Em verdade, a tutela coletiva nacional não é, a rigor, uma técnica que permite à coletividade expressar sua vontade ou seus interesses. Ao contrário, o que ela faz é autorizar alguns entes a, dizendo-se porta-voz de uma coletividade, defender os interesses desta". (2015, p. 218). Como a tônica do presente trabalho não gravita em torno de uma distinção a fundo dos institutos em epígrafe, as diferenças acima sublinhadas são suficientes para o propósito desta pesquisa.
} 
Nessa esteira é o argumento de Victoria Pasqualotto (2019, p.15), a respeito da insuficiência da sistemática processual para a tutela adequada de interesses 'multipolares':

Como é possível observar, tanto o processo individual como o coletivo no Brasil não conseguem ser meios para prestar tutela adequada, efetiva e tempestiva para os interesses multipolares. O modo como esses interesses vêm sendo tratados no âmbito do Poder Judiciário, além de sua manifesta inadequação, pode acarretar uma série de prejuízos. De um lado, para os titulares desses interesses: a falta de efetividade, a possibilidade de serem prejudicados pela má atuação de seu representante, os obstáculos à manifestação de sua vontade e direito de influência, assim como o beneficiamento de poucos interessados em detrimento dos demais são problemas muito recorrentes. De outro, para o Poder Público: a falta de racionalização do controle judicial da atuação do Poder Público pode gerar efeito contrário ao pretendido e, ao interferir indevidamente na execução de políticas públicas, prejudicar ainda mais a efetivação de direitos constitucionalmente assegurados. Além disso, o impacto dos comandos judiciais sobre os cofres públicos (e, consequentemente, sobre o planejamento orçamentário do Estado) ainda tem sua extensão desconhecida e, por ser feito de maneira desordenada, pode apresentar efeitos nefastos.

Edilson Vitorelli (2018, p. 333) identifica de forma muito precisa esses litígios estruturais, quando afirma que:

Em síntese, um processo estrutural é aquele que busca resolver, por intermédio da atuação da jurisdição, um litígio estrutural, pela reformulação de uma estrutura burocrática que é a causadora ou, de alguma forma, a responsável pela existência da violação que origina o litígio. Essa reestruturação se dará por intermédio da elaboração de um plano aprovado pelo juiz e sua posterior implementação, geralmente ao longo de um considerável período de tempo. Ela implicará a avaliação e reavaliação dos impactos diretos e indiretos do comportamento institucional, os recursos necessários e suas fontes, os efeitos colaterais da mudança promovida pelo processo sobre os demais atores sociais que interagem com a instituição, dentre outras providências.

Feitas as considerações acima, três são as diferenças fundamentais entre as duas modalidades de processo acima examinadas. Haja vista que o presente trabalho tem como recorte teórico o estudo do processo estrutural, desenvolve-se uma análise do tema proposto no contexto de possível desnaturação dos órgãos de proteção ambiental, em perspectiva interdisciplinar.

Por fim, vale anotar o que afirma Sérgio Arenhart (2020, p.143-144), ao tratar da necessária maturidade de um sistema jurídico, como requisito essencial para comportar esse tipo de processo estrutural

Compreendendo a lógica das decisões estruturais, surge como conclusão cristalina que não é qualquer sistema processual que possui as condições suficientes para albergá-las. Inicialmente é preciso um sistema jurídico maduro o suficiente para compreender a necessidade de revisão da ideia da "separação dos poderes", percebendo que não há Estado contemporâneo que conviva com a radical proibição de interferência judicial nos atos de outros ramos do Poder Público. Como dito, a satisfação desse requisito pelo direito nacional é algo já proposto, haja vista a sedimentada orientação do Supremo Tribunal Federal brasileiro, especialmente em atenção aos direitos fundamentais.

No tópico seguinte, e após considerações iniciais, traremos algumas considerações acerca da utilização desse tipo de medida para as ações em defesa do meio ambiente, conforme mencionado no item introdutório.

\subsection{Os processos estruturais e sua utilização para a defesa do meio ambiente como direito fundamental.}

Eduardo Cambi e Virginia Wrubel (2019, p.55) trazem uma relevante ponderação a respeito da utilização do processo estrutural para a defesa dos reiteradamente violados direitos fundamentais:

é certo que a judicialização de direitos sociais e o aparecimento de demandas estruturais, propiciadas pela ampliação do acesso à justiça, têm figurado como importante via para a efetividade dos direitos fundamentais, o que contribuiu 
para colocar o Poder Judiciário no centro das atenções da sociedade. Esse fenômeno, denominado judicial review, aproxima o direito da política, ao possibilitar que ações governamentais sejam contestadas perante o Judiciário ${ }^{7}$.

No tocante às supracitadas medidas estruturais, válida a lição de Sérgio Arenhart2013. p. 03:

Percebeu-se que muitas decisões sobre questões coletivas exigem soluções que vão além de decisões simples a respeito de relações lineares entre as partes. Exigem respostas difusas, com várias imposições ou medidas que se imponham gradativamente. São decisões que se orientam para uma perspectiva futura, tendo em conta a mais perfeita resolução da controvérsia como um todo, evitando que a decisão judicial se converta em problema maior do que o litígio que foi examinado. (ARENHART,).

Sem maiores esforços, seria possível vislumbrar claramente a potencialidade de litígios dessa natureza na seara ambiental.

Casos emblemáticos nos quais o Judiciário foi retirado de sua inércia para solucionar controvérsias como as catástrofes ambientais vivenciadas nos municípios mineiros de Brumadinho e Mariana, bem como o da Ação Civil Pública ${ }^{\circ}$ 93.8000533-4 (“ACP do Carvão”, validam o argumento referente às múltiplas possibilidades de afloramento de processos de caráter estrutural versando sobre questão ambiental.

Trata-se de situações nas quais a prestação jurisdicional não se limitou a decidir o mérito de acordo com as razões de fato e de direito carreadas aos autos, posto que a composição da lide clamou por decisões estruturantes em prol da manutenção/preservação dos valores mais caros à Constituição, tornados vulneráveis pelo próprio arranjo institucional e que vão, portanto, além do inicialmente pretendido.

Que fique claro, também, que nada disso anula a possibilidade de, havendo plena consciência de determinada necessidade estruturante, seja ajuizada ação que já tenha, de início, tal finalidade, o que já tem ocorrido, em especial, como decorrência dos recentes e lamentáveis desastres ambientais com barragens no Estado de Minas Gerais ${ }^{9}$.

Diante de toda a demonstrada insuficiência ou inconsistência de determinado arranjo institucional, associada a uma imbricação de interesses interdependentes quando da dedução em juízo de pretensões tais como as relatadas nos exemplos acima, descortina-se a possibilidade de se conclamar o poder Judiciário para que seja reestruturado o aparato existente.

Nessa linha de raciocínio é o escorço de Samuel Cota e de Leonardo Nunes (2018, p. 254), ao citar Lon Fuller: “os litígios estruturais são marcados pela policentria, com uma clara imbricação de interesses, todos relacionados e dependentes entre si e muitas vezes antagônicos, como a metáfora da teia de aranha utilizada por Fuller.”

Por fim, reacendendo a atualidade da questão, tem-se o advento da Lei n. 13.655/2018, cujo artigo 21, parágrafo único $^{10}$, prevê a possibilidade de implementação de técnicas processuais de tutela com características estruturais em litígios complexos que envolvam o controle da Administração Pública.

\footnotetext{
${ }^{7}$ Os autores complementam ainda, que: “é importante respeitar a reserva de consistência - isto é, o Estado-Juiz precisa apresentar argumentos substanciais de que o ato ou a omissão do agente público revela-se incompatível com a Constituição e que justifique a indispensável solução judicial. Igualmente, há de se observar o critério da subsidiariedade da judicialização, já que técnicas autocompositivas e de negociação assumem preferência (CPC (LGL\2015\1656), art. $3^{\circ}, \S 2^{\text {o}}$; Resolução 125/2010-CNJ; Resolução 118/2014-CNMP), dado que a elaboração de termos de ajustamento de conduta (TACs) pode se mostrar mais eficaz e evitar a eternização do processo judicial.” Litígios complexos e processo estrutural. Revista de Processo | vol. $295 / 2019$ |p. 55 - 84 | Set / 2019 DTR\2019\39965

${ }^{8}$ Nesse ínterim, remete-se o leitor do presente artigo à obra de Sérgio Cruz Arenhart (2015): Processos estruturais no Direito brasileiro: reflexões a partir do caso da ACP do carvão.

${ }^{9}$ A exemplo, no caso dos danos causados em decorrência do caso de Brumadinho temos - Autos do Processo

n. ${ }^{\circ}$ 5044954-73.2019.8.13.0024, ajuizada pelo MP MG - $1^{\text {a }}$ Vara Cível e Criminal da Comarca de Brumadinho - danos socioambientais e Autos do Processo n. ${ }^{\circ}$ 5087481-40.2019.8.13.0024 - danos socioeconômicos; Estado de Minas Gerais - Autos do Processo n. ${ }^{\circ}$ 5010709-36.2019.8.13.0024 e 502640867.2019.8.13.0024. Há também a ação proposta pelo Ministério Público Federal, eu requer intervenção da Companhia Vale S.A., para fins de “ desenvolver e posteriormente implementar um novo sistema de governança, trabalho a ser executado por interventor judicialmente nomeado, nos termos descritos no pedido de tutela provisória, até que seja possível aferir a total reestruturação das políticas e práticas internas da Vale, em termos de prevenção de desastres, em um patamar hábil a autossustentar-se no longo prazo" - Autos n. 1035519-02.2020.4.01.3800 - Justiça Federal da Primeira Região - 14 ${ }^{a}$ Vara Federal Cível da SJMG. Disponível em http://www.mpf.mp.br/mg/sala-de-imprensa/docs/2020/inicial-acp-vale-anm-cvm.pdf. Último acesso em 28.12.2020.
} 
Nesse giro, afirma Fernando Menegat (2018, p. 12) que o excerto supramencionado "oficializa, no Brasil, o Processo Estrutural como técnica processual idônea para a implementação e efetivação de decisões, judiciais ou extrajudiciais, exaradas em face da Fazenda Pública nos processos de controle". Interessante pontuar que a premência do Processo Estrutural é notada, primordialmente, nas lides envolvendo a Administração Pública ${ }^{11}$. Afinal, a implementação e/ou o controle judicial de políticas públicas revela-se como o terreno fértil àquelas decisões ditas estruturantes, isto é, de eficácia multilateral.

O Superior Tribunal de Justiça já reconheceu a necessidade de tratamento de litígios de forma estrutural. Manoela Virmond Munhoz (2020, p.231) analisou o Recurso Especial 1.733.412/SP, em caso recente e bastante interessante, no qual se discutia a necessidade de melhorias no serviço público de saúde prestado pelo Hospital Ermelino Matarazzo. A ação foi julgada improcedente, porque o TJSP entendeu que a atuação necessária fugia à sua competência. O Superior Tribunal de Justiça, por sua vez, entendeu que a complexidade do tema, e seu fundamento, direito à saúde, portanto, um direito fundamental, justificava um tratamento diferenciado. ${ }^{12}$

\section{Considerações Finais}

A complexa dinâmica de uma sociedade multifacetária exige uma ressignificação da sistemática processual.

O imbricamento de interesses subjacente à discussão de um problema estrutural, demanda uma tutela processual ressignificada. Isto é, um clama por mecanismo adequado para uma reestruturação do estado de coisas até então desconforme desestruturado.

O cenário recente, notadamente em razão dos desastres ambientais ocorridos - em Mariana e Brumadinho - bem como a devastação da fauna, somados a uma possível necessidade de reorganização do arranjo burocrático, descortina-se terreno fértil para o processo de caráter estrutural.

A procedimentalidade inerente ao aludido processo de caráter estrutural possibilita a transição de um estado de violação sistemática do direito ao meio ambiente ecologicamente equilibrado, para uma realidade de maior conformidade com o ideal de efetividade dos direitos fundamentais.

Finalmente, a partir da proposta inicialmente desenvolvida, descortina-se possível uma pesquisa, em trabalho futuro, de técnicas específicas voltadas à proteção ambiental no cenário acima verificado. Isto é, após uma fase de reconhecimento do problema estrutural de cunho ambiental, pertinente investigar os contornos da decisão estrutural e a intensidade do impacto quando da implementação do regime de transição a ser estabelecido. Por fim, abre-se campo para o exame da fiscalização e avaliação pelo magistrado do próprio cumprimento em tempo razoável das regras de transição estabelecidas.

\footnotetext{
${ }^{10}$ Art. 21: A decisão que, nas esferas administrativa, controladora ou judicial, decretar a invalidação de ato, contrato, ajuste, processo ou norma administrativa deverá indicar de modo expresso suas consequências jurídicas e administrativas.

Parágrafo único. A decisão a que se refere o caput deste artigo deverá, quando for o caso, indicar as condições para que a regularização ocorra de modo proporcional e equânime e sem prejuízo aos interesses gerais, não se podendo impor aos sujeitos atingidos ônus ou perdas que, em função das peculiaridades do caso, sejam anormais ou excessivos. (ANGHER, 2020)

${ }^{11}$ Conforme aponta o próprio Fernando Menegat (2018).

${ }^{12}$ A temática dos processos estruturais tem sido cada vez mais explorada pela doutrina brasileira e, mais recentemente, chegou à atenção do Superior Tribunal de Justiça. O acórdão proferido pela Segunda Turma no âmbito do Recurso Especial 1.733.412/SP, de relatoria do Ministro Og Fernandes, reconheceu a necessidade de adoção de um modelo de processo do tipo estrutural para tratar de litígio complexo oriundo do Tribunal de Justiça do Estado de São Paulo, que envolvia melhorias no serviço público de saúde prestado pelo Hospital Municipal Prof. Dr. Alípio Correa Neto - Ermelino Matarazzo, localizado na cidade de São Paulo.

O tribunal de origem havia deixado de interferir na problemática estrutural do Hospital, reconhecendo que se tratava de providência que fugia à sua atuação, cujo enfrentamento implicaria indevida interferência na esfera administrativa. Porém, não foi essa a compreensão do STJ, que expressamente aduziu se tratar de litígio do tipo estrutural, o qual demandava atuação diversa do Judiciário, tendo em vista o direito fundamental sub judice - naquele caso, o direito à saúde. Ao assim compreender, o STJ proveu o Recurso Especial do Ministério Público do Estado de São Paulo (MP) para determinar o retorno do feito à origem, a fim de que fosse sanada a atuação omissiva das instâncias ordinárias no caso. O reconhecimento, pelo superior tribunal de justiça, dos processos estruturais como necessários à solução de litígios complexos: uma análise do Recurso Especial 1.733.412/SP. Revista de Processo | vol. $308 / 2020$ | p. 231 245 | Out / 2020. DTR 2020\11487
} 


\section{Referências}

Amazon fires: Are they worse this year than before? - BBC <https://www.bbc.com/news/world-latin-america-53893161>

Angher, A. J. (2020) Vade Mecum Universitário de Direito. (27a ed.), Rideel.

Arenhart, S. C. (2020) Curso de Direito Processual Coletivo. (2a ed.), Editora Revista dos Tribunais.

Arenhart, S. C. (2013) Decisões estruturais no direito processual civil brasileiro. Revista de Processo. 225.

Arenhart, S. C. (2015) Processos estruturais no Direito brasileiro: reflexões a partir do caso da ACP do carvão. Revista de Processo Comparado. 2, 211-229

Brasil. Constituição da República Federativa do Brasil de 1988. Brasília, DF: Presidência da República, 2019. <http://www.planalto.gov.br/ccivil_03/constituicao/constituicaocompilado.htm>.

Cambi, E., \& Wrubel, V. (2019). Litígios complexos e processo estrutural. Revista de Processo, 295/2019, 55 - 84

Chayes, A. (1976) The role of the judge in public law litigation. Harvard law review. 89(7), 1281-82. https://heinonline.org/HOL/AuthorProfile?base=js\&search_name=Chayes, \%20Abram\&1==1583357574

Cota, S. P.; \& Nunes, L. S. (2018). Medidas estruturais no ordenamento jurídico brasileiro: os problemas da rigidez do pedido na judicialização dos conflitos de interesse público. Revista de Informação Legislativa, Brasília, 55(217), 243-255.

Didier Jr., F. Braga. P. S.; \& Oliveira, R. A. (2020) Curso de Direito Processual Civil. 2. JusPODIVM. Salvador.

Fiss, O. (2018). As formas de Justiça. In: Costa, S. H.; Watanabe, K. Grinover, A.P. (Org.). O processo para solução de conflitos de interesse público. Salvador: JusPODIVM, 119-173.

Gomes Junior, L. M., \& Cruz, L. P. F. (2019) Ações coletivas passivas: um diálogo com a doutrina - Primeira Parte. São Paulo, RePro, 287,291 - 305.

Gomes Junior, L. M. (2008) Curso de Direito Processual Civil Coletivo. (2a ed.) SRS. p. 14.

Grinover. A. P. (2016). Ensaio sobre a processualidade: fundamentos para uma nova teoria geral do processo. Brasília: Gazeta Jurídica.

Koche, J. C. (2011). Fundamentos de metodologia científica. Vozes. http://www.brunovivas.com/wp-content/uploads/sites/10/2018/07/K\%C3\%B6cheJos\%C3\%A9-Carlos0D0AFundamentos-de-metodologia-cient\%C3\%ADfica-_teoria-da0D0Aci\%C3\%AAncia-e-inicia\%C3\%A7\%C3\%A3o-\%C3\%A0pesquisa.pdf

Jobim, M.F. (2013). Medidas Estruturantes: da Suprema Corte Estadunidense ao Supremo Tribunal Federal. Livraria do Advogado Editora.

Menegat, F. (2018). A novíssima Lei n. 13.655/2018 e o Processo Estrutural nos litígios complexos envolvendo a Administração Pública. Direito do Estado, Curitiba, $396 . \quad<$ http://www.direitodoestado.com.br/colunistas/fernando-menegat/a-novissima-lei-n-13655-2018-e-o-processo-estrutural-nos-litigioscomplexos-envolvendo-a-administracao-publica.>

Pasqualotto, V. F. (2018) O processo civil entre litígios tradicionais e litígios multipolares complexos: a resposta do processo estrutural. Trabalho de Conclusão de Curso (TCC) no Direito.

Reckziegel, J., \& Castro, M. F. de. (2013). Em busca do paraíso distante: em torno de alguns obstáculos à efetivação dos direitos fundamentais. Revista de Direitos e Garantias Fundamentais. (13), 31-48.

Violin, J. (2013) Protagonismo judiciário e processo coletivo estrutural. JusPodivm.

Vitorelli, E. (2018) Levando os conceitos a sério: o processo estrutural, processo coletivo, processo estratégico e suas diferenças. Revista de Processo. $284 / 2018,333-369$

Yeazell, S. C. (1980) The ordinary and the extraordinary in institutional litigation. Harvard law review. 93(3). <https://www.jstor.org/stable/1340545?seq=1> 